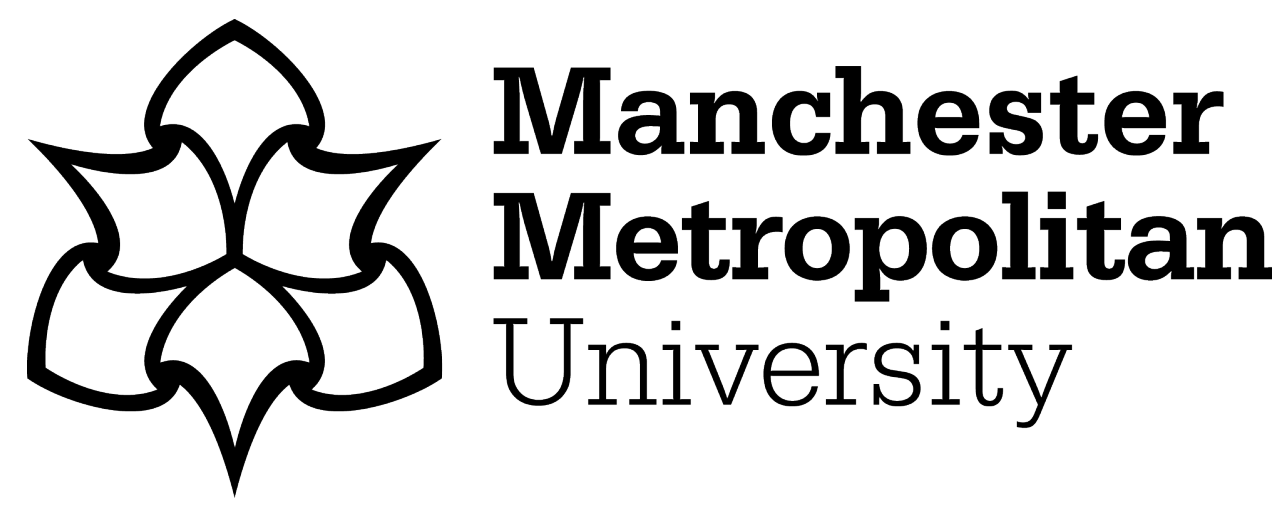

Peter, Beate ORCID logoORCID: https://orcid.org/0000-0003-4136-7733 (2020) Rave journeys: Intimacy, liminality, and the changing notion of home. In: Popular Music and Automobiles. Bloomsbury Publishing USA, pp. 83-96. ISBN 1501352326

Downloaded from: https://e-space.mmu.ac.uk/625266/

Version: Accepted Version

Publisher: Bloomsbury Publishing USA

Please cite the published version 


\title{
Rave journeys: Intimacy, liminality, and the changing notion of home
}

\author{
Beate Peter
}

Historically, raves in Britain were understood to be outdoor, electronic dance music gatherings which took place in particular geographical spaces. Their sites were often located just outside of cities, and it was not uncommon for raves to happen in locations accessible only to those who drove or knew someone with access to a motor vehicle. Despite the crucial role that cars, vans, and buses played for visitors to be able to participate, the importance of ravers' journeys has been largely ignored by music historians. This chapter presents the results of interviews with people who used to go to raves by motor transport. Between December 2017 and January 2018, semi-structured interviews were conducted with eight such participants. All self-identified as having been to raves in Greater Manchester, and beyond, between 1985 and 1995. The respondents were a selfselected sample of committed contributors to the Lapsed Clubber project who had all been involved in research for this project for a couple of years. ${ }^{1}$ None of them owned a car during their rave-going days, so they all depended on others' willingness to offer lifts. Interview questions were designed in order to ascertain their motivations for rave journeys, discover the conditions under which people travelled, and understand the social significance of the car as an immediate means of transport. George McKay has claimed:

One central way in which cultures of resistance define themselves against the culture of the majority is through the construction of their own zones, their own spaces. These can be distinguished in part through the subcultural elements of music, style or favoured drugs (if any-there usually are), but space itself is vital.

$(1996$, p. 7) 
For rave, this space was the English countryside (see, for example, Hill, 2002; John, 2015). Transport in the form of cars or vans was vital to get to key places in the countryside, and the crucial role that automobile journeys played-namely, to provide a safe space for people to develop a notion of home and belongingwas dismissed once raves were criminalized. Drawing on my interviews, this chapter discusses the significance of the car journey in the wider context of the rave experience.

It is important at this point to distinguish between early rave culture and club culture as it is understood today. Steve Redhead (1993, p. 4) defines early rave culture as being both a youth culture and a 'deviant' activity. At the same time, however, he acknowledges rave culture's embrace of materialistic values and commercial practices. Some scholars argue that this embrace was the result of Thatcherism (Hill, 2002; John, 2015; McKay, 1996). However, the "double relationship between the subculture and Thatcherism ... reaches beyond simple opposition" (Hill, 2002, p. 91) and allowed a youth culture to develop alternative practices while fully engaging in entrepreneurial activities and commercializing a subculture. "Rave culture's ability to alternately contest and mimic Thatcherite ideology" (John, 2015, p. 162) might be the reason why George McKay (1996) struggles to see rave culture as a counterculture in a historical sense. And yet, McKay presents rave culture as part of a tradition of free festivals in Britain. In doing so, he provides a narrative of countercultural values that did not appear out of nowhere. Instead, he argues that the cultures of resistance (which include rave) partly "constitute a politics of the disenfranchised, wherein the youth and marginal left out of Thatcher's revolution find their voices and use them to express their resentment and opposition" (p. 1). McKay traces the values informing those voices back to the 1960s, thus allowing us to read rave culture as part of a legacy that is represented by rave's PLUR (Peace, Love, Unity, Respect) ethos: "Castlemorton was literally a displaced hippy event" (1996, p. 120).

Not all members of 1980s to 1990s youth culture internalized or celebrated the PLUR ethos, either across the whole demographic or for the initial period that rave existed. Redhead characterizes rave events as having been "notorious for mixing all kinds of styles on the same dance floor and attracting a range of previously opposed subcultures from football hooligans to New Age hippies" (pp. 3-4). Members of previously different subcultures harboured diverse values. McKay also hints at the fact that even within the traveller scene, motivations and values were shifting at the time, and that moving goalposts allow for the amalgamation of different youth cultures (p. 71). He states that "the pinnacle 
of the festival/rave crossover to date was undoubtedly reached at Castlemorton Common in Hereford and Worcester in May 1992" (1996, p. 120). McKay argues that the 1994 Criminal Justice and Public Order Act-commonly referred to as the Rave Bill-presented a most oppressive piece of legislation that criminalized rather than challenged certain lifestyles associated with raves, but not limited to ravers. The affected groups shared certain lifestyle aspects, including the free use of open land and the playing of music at these sites. With the prohibition of such practices, rave culture's transformation into a fully commercial mainstream culture seemed logical. Brian Ott and Bill Herman (2003) argued that the changing rave sensibility from a countercultural resistance towards its commodification resulted in a loss of "transgressive potential" (p. 249). I argue that this 'potential' was partly formed during rave journeys.

Like McKay, Jaimangal-Jones, Pritchard and Morgan (2010) note that space plays a crucial role in the construction of dance music culture. They argue that event spaces (festivals) are "places which, whilst on one level ... are operational entities, can also be interpreted as liminal thresholds of transition and transgression" (p. 253). Jaimangal-Jones et al. place particular importance on the role of the journey to create a specific space in which a culture can flourish. They state that "travel to dance events is socially constructed by their participants both as a rite of passage and as a pilgrimage or source of spiritual fulfilment" (p. 254). Ott and Herman (2003) similarly assert that "the secrecy surrounding the location of underground raves also served to heighten a sense of community by uniting ravers in specialized knowledge and transforming the quest for the location into a ritualistic pilgrimage" (p. 24).

Findings from the interviews established that car journeys functioned as community-building processes upon which a positive rave experience could be based. Generally, all passengers, including the driver, would participate in the rave. The journey itself became understood as starting when the driver picked up fellow passengers and spent time at their flats or houses. Individual processes linked to each part of the picking up led to the establishment of strong bonds between the passengers. This impacted on their sense of physical and mental wellbeing, and helped to create a safe space inside the car, once all passengers were collected. Themes that emerged from the interviews highlighted how important each journey was for the overall rave experience, not only as a means of getting to and from the rave itself but also as a base during the rave. Each vehicle was a chill-out room, a drug den, and a meeting point, all in one. This space became crucial for the rave itself, as people would feel listened to, looked after, and cared 
for-and all of this before the dance spectacle had even started. In this chapter, I therefore argue that ravers developed an idea of home and belonging that was not built on geography but instead based on social bonding during a car journey. It was this idea of an emotional and spiritual home of bonding with fellow ravers that shaped early rave culture, both within and in relation to wider society. The chapter therefore seeks to explain the importance of rave journeys, particularly the ways that they physically and mentally facilitated intimacy and helped to develop a sense of community prior to the participants arriving at the rave.

\section{Getting ready, or fine-tuning, for the journey}

During the interviews it became clear that getting ready, in the context of a rave, could refer to three distinct types of activity. These not only helped people focus their minds on the forthcoming rave, but also helped them to adjust to one another.

First, ravers would get specially dressed for the event. However, in the context of raves that could mean something completely different to what might be inferred. Respondent 6 commented on his ritual of dressing up as dressing down. Dressing down, for this raver, was meant to distinguish himself from the 'Balearic heads,' a group of other dancers that would exhibit not only other clothing accessories but also a different behaviour. Here, reference was being made to style (sub)cultures and their desire to distinguish themselves from perhaps more prominent cultures. This discussion, in Britain, is mainly informed by the work of scholars belonging to the Centre for Contemporary Cultural Studies (CCCS) in Birmingham in the 1960s and 1970s, who focused mainly on class belonging, but also on style, as an expression of opposition and resistance. Respondent 6 , however, a male respondent, referred to dressing down as a new-found freedom.

Previous dance experiences in the city not related to house music required men to wear shirts, ties, and shoes rather than trainers. A lack of dress code at raves was experienced as both personal and physical freedom: personal in that a choice was given as to what one can wear, physical because the clothing would facilitate dancing. Baggy trousers and lose-fitting $t$-shirts became associated with rave culture for quite some time. And yet, tight-fitting clothes also featured on the rave scene. The first respondent referred to a ritual of dressing up in such clothes and characterized the rave experience as beginning with the choosing of 
clothes. One could argue that the anticipation would start to build when people began to dress up. The level of anticipation would increase over the course of an evening, as arriving at the site of the rave was hours away.

Secondly, getting ready could also mean that the driver would pick up their fellow passengers or pieces of music equipment (something mentioned by half of the respondents). That ritual would often involve a stopover. In this context, the journey would involve not only driving from one place to another but also socializing with potential fellow passengers before setting off for the actual rave. This social aspect of the pickup allowed passengers to co-create a positive, trusting atmosphere that set the tone for the journey. Because of the preliminary interactions, any inhibitions that might prevent people from creating and enjoying an intimate atmosphere in the car could be overcome, in other words, meeting up with fellow passengers before being squeezed into a car allowed everybody to bond. At the same time, it increased the level of anticipation, especially when rituals associated with the rave space were practised. These rituals, according to respondents 4,5 , and 6 , included taking drugs as well as dancing in somebody's private space. Occasionally, it would mean, according to respondent 4 , that they "would have taken all the drugs before setting off and peak somewhere in the middle of nowhere, stuck in the car." This experience had to be facilitated, and the mutual support that people gave each other, before as well as during the drive, would enhance the process of forming a strong bond with fellow passengers.

Thirdly, getting ready could also be understood as a way of building critical mass, often achieved by meeting other ravers (and their cars) at service stations. All respondents commented on the effect that meeting fellow cars on the journey had on their mood and levels of anticipation. Four and five commented on their feelings of exhilaration when spotting other 'rave cars' at service stations. Recognizing that others were part of a group that was about to engage in illegal practices generated a strong bond between people that might never have met before. Knowing about other people's intentions was crucial for the sense that they were going on an adventure together. It began to generate a shared perception that there was a critical mass of rave goers.

The interviews revealed that each rave journey encompassed more than an actual drive from a geographic origin to destination. Rituals preceding the drive were important for the people who became fellow passengers, as they allowed them to establish a strong bond, and to be on the same wavelength before entering the confinements of a car. Those preconditions had to be met in order for a joint drive to become a transformative experience. 


\section{The drive}

All of the people who were interviewed about their journeys confirmed that they would never share a journey with people they did not know. Other participants had to be friends, or friends of good friends, in order for everybody to be willing to share the car. All but one respondent referred to the close-knit Manchester rave community where everybody would know everybody else, and it would be the same set of people who would travel to raves outside of the city. As respondent 2 confirmed: "You would see the same faces in Manchester, Leeds, Sheffield, Liverpool and North Wales. It was almost like a tribe moving to different locations in search of the ultimate rave experience." The respondents explained the importance of mutual acquaintanceship with the practices that passengers engaged with during the journey, and the threshold level of trust that was needed in order to enjoy those experiences. Contrary to popular assumptions, building trust included not just practices related to drug taking but also sharing conversation topics, listening to music together, or lying to the police when stopped on the way to a rave.

Most of the respondents referred to the vehicle as an intimate space. Respondent 1 referred to it as a "mini living room" because "you would talk, come down together, be silent together, listen to music together and take drugs together." The level of intimacy experienced inside the car was sometimes described as making you feel safe and protected, similar to a 'cocoon.' The fact that the 'mini living room' was not stationary, but mobile, meant that a protective environment created by both the car and its people transported the passengers 'safely' to the site of the rave.

In their study, Jaimangal-Jones et al. (p. 257) found that "a journey can heighten the enjoyment of a dance event as it increases the build-up and excitement; indeed, often the greater the commitment and effort required reaching an event, the more it was anticipated and enjoyed." The first five respondents in this study confirm this point. They provided examples of trips to the countryside in North Wales, which verified that the level of excitement would increase the longer the journey took. The duration of the journey was not necessarily linked to geographic distance, respondent 1 explained. Journeys could be prolonged because of the exact destination of a rave being unknown. Also, being stopped by the police in remote places and lying about the destination of the car journey, according to the first two respondents, had a positive impact on the level of excitement. Moves to define the rave journey as both starting with rituals of 
getting ready and involving the drive itself can be seen as a tool to build up positive emotions. However, they can also be understood as facilitating or being part of, an act of transition.

Although music and drugs might already have featured in people's houses before driving to the rave, being together in a car meant that each transgressive journey could include the change from the city to the countryside. Respondents repeatedly pointed out the fact that in the 1980s and 1990s, people did not have mobile phones nor were they able to use satellite navigation systems in their cars. Leaving the city with signposts aplenty and attempting to find a secret location in the countryside was almost a journey by instinct. Anecdotes from respondents 1,2 , and 4 included hours of searching for the right location, often attempting to follow the music. In a sense, this experience could be described as 'homing: people returning, almost by instinct, to their territory. It is what McKay (1996, p. 7) describes as the construction of zones for cultures to engage with their specific practices. Additionally, raver territoriality effectively involved arriving at a site of rupture from everyday life. Jaimangal-Jones et al. (2010, p. 257) compare the change of an "individual's self-consciousness and conformity to social roles" in such zones with the behaviour of tourists in unfamiliar surroundings, only that the ravers developed a sense of arriving 'home' when reaching the site of a rave.

\section{The notion of home}

At the time for all of the respondents, the notion of home was strongly linked to a community of like-minded ravers rather than to a particular geography or family. One of the reasons why this community felt so tight-knit was, perhaps, the understanding of its members that their experiences were not ordinary. By leaving the city behind and producing meaning in the countryside, ravers became resistant bodies, refusing the division of life into opposites: day and night, work and leisure, us and them, or buying and selling. Respondent 4 remarked on how the lack of buildings that are frequented by office workers or shops with specific opening and closing times also added to a feeling of suspense and "the capitalist world was left behind." The nurturing of a specific positive atmosphere, the building up of excitement, and high levels of anticipation-all of them experienced in the car-meant that people were ready to embrace the rave once they had arrived. For all but one respondent, that process of embrace included interaction with other ravers at the site. In fact, according to respondents 1 , 
4 , and 5, fellow passengers would rarely stay together at the rave but instead meet and engage with other people. Again, respondent 5 commented on how they would always end up talking to strangers, often for hours on end. Some of those people they would never see again. Others would become friends for life. Respondent 3 associated the making of memories with the making of friends. That would not just include the people who they had shared a journey with but also new people that they would meet at the site of the rave. It suggests that a certain attitude existed among the ravers, and it included openness towards strangers, trusting them to be part of a community that jointly created the rave.

Practising the community ethos, all respondents reported that the cost for the journey would always be split, and respondent 1 noted that typically they would be inclined to "pay over the odds" because you would want a lift next time. Payment was not always in the form of money, but could also be in the form of drinks or drugs (respondent 4). Also, all passengers on a journey were aware they were engaging in risky behaviour. The risk of being stopped by the police while trying to find a rave was permanent and made them come closer to one another (respondent 4). The secrecy of, and communication about, locations had a similar impact on the bonding as a community. The notion of being part of a culture that is different to the model of youth, that is advocated through the media and enforced through policies, acted as another bonding agent. Although respondents 4 and 5 stated that being part of rave culture was related to getting to know new music and to being able to dance, the sound systems at raves were often bad. This is partly linked to the DIY ethos that existed at the time and the fact that sound equipment had to be taken to remote places in the same way as ravers travelled to such sites. As many raves were based on donations, professional equipment would not be rented, but borrowed instead. Half the respondents explained how the sound systems that they helped transport would be collected from various houses that were visited before people set off to leave the city. Sound systems and collectives were each known for their particular music style, but people did notrespondents 4,5 , and 6 noted-seem to be too selective over the kind of music that would be played at a rave. In this regard, the idea of home was also linked to a particular attitude towards capitalist commerce. All respondents except for 3 and 7 commented on the role of new music as constituting resistance. The period in question preceded internet radio, file sharing, and digital music production, so going to events was often the only opportunity to actually consume new music. Meeting to hear new music was perceived as a form of activism, and the unknown -in this case music - was not feared but embraced. 
The celebration of the community spirit stood in direct oppositionaccording to respondents 4,5 , and 6 -to the values that ravers perceived to be promoted by a Thatcherite government: individualism, private entrepreneurship, and an assumption that all people are driven by the desire to climb the social ladder. Such resistance to conformity did not exclude entrepreneurial activities. Motivation for such activities lay in the desire to create a community in spirit, one that could "have the potential to change the world" according to respondent 4; they referred to a sense of unity and belonging and their belief that the rave community would be able to change society: "We felt that something bigger was about to happen." The respondents did not, however, perceive rave culture's exploration of its commercial potential as exclusively negative, as bigger raves were seen as opportunities to experience more new music on the one hand, and gathering momentum on the other.

All respondents confirmed that their reason to drive to a rave was to dance. Through dance, ravers defined their (counter)cultural spaces and their relationship with fellow ravers. It was through dance that new music was experienced on a physical level. According to McNeill (1995), dancing together for a prolonged period of time is a form of muscular bonding that shifts the focus away from the individual towards the community. He argues that, similar to marching, dancing together in sync allows people to experience "muscular manifestations of group solidarity" (p. 10). McNeill goes on to suggest:

An important feature of emotional bonding through rhythmic muscular movement is that it affects those who take part in it more or less independently of how they may have been connected (or divided) by prior experience. Hence dance could and did become a way in which all sorts of new groups could define themselves, both by differentiation from within existing communities and by allowing marginalized persons or complete outsiders to coalesce into new, more or less coherent groups. (p. 52)

Over half the respondents referred to a spiritual home that was created by being part of the rave community, and, from this safe space, long-lasting friendships were built. Those friendships transcended into everyday life and blurred the lines between countercultural spaces and civic life. All respondents described the period between 1985 and 1995 as a time in which they experienced significant sociocultural changes. For some, those changes were experienced as rupture and, at the same time, as an opportunity to experiment with new forms of community. 


\section{Liminality}

The feeling of being totally free at a rave was described by all respondents in one way or another. In a field, according to respondent 4 , ravers were not confronted with the visual cues of civic life and the unspoken requirement to engage with it. Respondents referred to the absence of (rush hour) traffic, office workers, and public buildings; Goethe's words seem quite fitting here when he says "music is liquid architecture; architecture is frozen music" (reproduced in Sussman and Hollander, 2015, p. 129). It appears that the kind of music that was played at raves not only created a countercultural spiritual space but also created associations with the actual landscape and architecture in which raves would take place. The suspense of time was clearly felt, at least for respondents 4 and 5 , because rural areas did not provide the typical time markers that people would experience in the city-for example, opening and closing times of shops, peak travelling times, or even public clocks. Another aspect that promoted the shared sense of being in a liminal space was the idea that nobody knew when the rave would end. An absence of schedules and timings allowed people to fully immerse themselves in the moment without thinking ahead in time and thinking of possible (negative) consequences. Apart from witnessing day and night in the open, ravers would be unable to fit their experience into the everyday framework of a working day or even a 'normal' weekend; this impossibility of mapping the experience against ordinary life was embraced.

In addition, the lack of physical boundaries such as walls, buildings, or roads added to the experience, for respondent 5 , of being removed from the everyday. The same applies to the notion of being somewhere far away from civilization, as the absence, according to respondents 4 and 5, of 'normal people' such as shop owners, ordinary dwellers, or inhabitants was strongly felt. Being 'alone together' was described by respondent 5 as "being away from people who do not belong but being together with people who do belong." I argue that 'the rave car journey' also fits this description, and by 'the rave car journey' I also mean the return trip.

\section{The journey back}

Until now, journeys in relation to raves or big EDM gatherings have been discussed only with regard to getting to these places. However, the journey to a rave is fundamentally different to a journey leaving the rave, not least because, 
as over half the respondents said, the destination of your return journey was not always your physical home or the place you started your journey. Respondents 4 and 5 described the return journey as being of the same liminal quality as the rave itself. They both agreed that it was unknown when the rave would end. This meant that passengers did not quite know when to congregate in order to drive back. Uncertainty about the agreed departure time was embraced rather than dreaded, as it allowed ravers to enjoy the moment without having to plan ahead or even position the rave experience within a wider context of everyday life. And yet, all respondents agreed that it was the driver who would decide when to leave the rave. The role of the driver is of importance in this context and needs to be discussed further.

Considering that all respondents said that they would know the driver, and not enter the car if this person was not known among friends, three respondents noted that they also needed absolute faith in the driver and trusted that they would always get home. The first two respondents explained their attitude towards the driver needing to "stay straight" with previous traumatic experiences. Other respondents blindly trusted the driver's ability to be in command of the car, regardless of their level of intoxication. Respondent 6 said that "back in the days everybody thought that you could drive on pills." 'They go on to explain that there was this myth that mixing alcohol and MDMA was not good, so people chose MDMA over alcohol, and assumed that MDMA or other drugs did not have as profound an impact on the driver's ability as alcohol. Respondents 4, 5, and 6 agreed that there would be ways in which the driver's decision to leave a rave could be influenced; providing drugs for the driver was one of them.

Occasionally, a driver would be rented together with a minibus, so that all passengers could fully engage in the event. On those occasions, according to the first two respondents, the driver would wait in the car or minibus and a time would be arranged to start the return journey. That was not necessarily the case when the driver was from within the rave community. The car constituted a meeting point during the rave, and people would treat it as an intimate space, to which they could retreat. Ravers would regularly move, according to respondents 4 and 5 , between the overall dance space and the car to catch up with the driver. It provided an antidote to what was happening at the rave: the rave knew no physical boundaries, but the car was small and intimate; raving meant active participation for hours or days on end, whereas retreating to the car provided an opportunity to rest. For respondents 4,5 , and 6 it constituted an alternative venue, in which the suspense of time was felt even more than at the rave. 
The way that ravers described their transitioning between the intimate space of the car and the wider rave space suggested that there was a need for people to retreat temporarily in order to immerse themselves in the bigger event for a prolonged period of time. The atmosphere created in the car, even before driving to the rave, constituted a crucial element for passengers who dispersed once they arrived, but were then able to return to intimacy inside the car when they left the rave together.

Each return journey was fundamentally different to the journey at the beginning of the night. Often, people would not listen to music but talk or, in fact, be silent together. Regardless of the mood in the car, all respondents confirmed that you would look out for one another during the journey. Arranging breaks, supplying water, resting, turning down the music, or engaging another person in a conversation were all reactions to a fellow passenger in need. The idea that people would look out for one another increased the level of intimacy and added to the notion of not only being in when respondent 1 called a 'mini living room' but also being with one's family, according to respondent 4 , with regard to care, respect, and empathy.

Not knowing where you were going was not just something experienced during the drive to the rave but also extended to the return journey. Respondents commented on the desire to extend the rave at other locations, but with the level of intimacy that was felt in the car. Ravers would sometimes drive to other remote places in the countryside or to somebody's house. Half the ravers mentioned that the desire to stay together as a group was felt very strongly and would only be overridden by the need to go to work or similar such commitments.

Later, things changed. Respondents 4, 5, and 6 struggled to establish a causal relationship between the change in music ("it became," as one noted, "cynical and dark"), the changing effects of ecstasy pills ("they became trippier," said respondent 6), and the change in the character of events (most respondents said when "alcohol appeared and people became more aggressive"), but they all agreed that the general atmosphere in the rave community transformed. The rise of the superstar DJ was commented on, as well as the establishment of super clubs; both of those were identified as being part of a changed rave culture.

\section{Conclusion}

Journeys by means of cars or vans form an important part of early rave culture, not least because the events themselves took place outside the city, and it was 
impossible to reach many locations by public transport. The car, then, can be seen as an enabler for participation in raves. Each vehicle, however, was not just a means of transport but also a safe space in which an intimate relationship with fellow passengers was formed or maintained. Several factors contributed to the car being understood as a safe space: its size, joint listening to music, the knowledge of engaging in illicit practices, and a joint sense of adventure as the rave had to be found.

This chapter has shown how the perceived protection that the car provided on the journey was also the result of a build-up of mutual trust and a form of fine-tuning of moods hours before the drive. Because of this, the car journey has to be understood as an experience that starts much earlier than the actual drive. First, the rave experience started for many with the ritual of getting dressed. The practice was presented here as an act of freedom (of choice) that was in stark contrast to the dress codes required by nightclubs in the late 1970 s and early 1980 s. The absence of a formal dress code for raves was a sign of individuality and freedom of expression; something that rave culture embraced through its inclusive approach. Secondly, picking up fellow passengers was another crucial element to the rave journey, as the time spent in other ravers' houses prior to departure allowed people to adjust and adapt their moods and create the intimate atmosphere that would be intensified when people entered the confinements of the car. Finally, meeting up with cars full of other ravers at service stations was important because participants felt the build-up of critical mass and momentum, which, in turn, impacted on their sense of belonging to a specific counterculture. That feeling of belonging to a strong, close-knit community of like-minded people did not end at the rave. In a similar way to the outward journey, the intimacy of the car facilitated communication and further bonding. A form of decompression was possible when fellow passengers decided to spend more time together by driving to other locations.

Taken those aspects together, the rave journey itself has to be recognized as a liminal experience, both physically and mentally. Leaving the familiar landscape of the city, home town, or village to drive to a remote field, ravers would experience geographical detachment. Entering an unlicensed, unregulated space facilitated a liminal experience. This was further helped by the absence of physical boundaries at the rave and an undefined dance floor. In addition, raves did not operate within time limits; curfews were not enforced. Consequently, the whole rave journey was celebrated by its participants as an experience suspended beyond time and space. 
When basic conditions were met, ravers could redefine their idea of a home both geographically and mentally. Forming bonds with like-minded people that were perceived to be stronger than blood relations is one such result. Longlasting friendships transcended the boundaries of rave culture and helped to incorporate rave values, as expressed through the PLUR ethos, into everyday life. This understanding of rave culture provides an alternative reading to the common assumption of rave culture having been an apolitical, purely hedonistic culture that had no significant impact on people's lives.

What does this mean for analysing current club culture? The sonic landscape of electronic dance music has changed so much that it has become almost impossible to compare it with early rave culture. And yet, there are developments in which one might be able to find traces of early rave culture. The festival market, for example, has changed considerably over the past few years. According to UK Music, the number of people who attended live music events rose by 12 per cent between 2015 and 2016. That equates to almost 4 million people attending festivals in the UK $(2017$, p. 6).

It is worth mentioning that 67 per cent of festival goers still travel by car according to the UK Festival Awards' Market Report 2017 (p. 5). Contemporary car journeys can last for hours and, like rave journeys, they take passengers to a site of suspense both in terms of time and space. Music is stated to be the most important reason for attending a festival (64 per cent), followed by a concern to hang out with friends (19 per cent). There seems to be a clear desire to connect with other people and to spend prolonged periods of time together. Interestingly, the second most prominent age group after twenty- to twentyfive-(18 per cent)-year olds were forty- to fifty-year olds (18 per cent)-people who enjoyed their teenage years during the second summer of love in 1989, and the explosion of acid house in the UK. So, one could wonder whether old ravers are discovering festivals, rather than nightclubs, as sites to continue or repeat their rave experiences.

To finish, I will outline some directions for future research based on the findings presented in this chapter. Such research could explore the similarities and differences between early rave culture and contemporary festivals in more detail. Can festival sites be seen as similar sites of liminality? What role does the journey play? Is there a shared ethos that is common to all festival goers? Do experiences at festivals have a similar impact on people's everyday lives to the impact rave culture had? Finally, how are these experiences contextualized by their participants? 